\title{
Real Time Water Quality Measurement System based on GSM
}

\author{
Akanksha Purohit ${ }^{1}$, Ulhaskumar Gokhale ${ }^{2}$ \\ ${ }^{I}$ Department of Electronics \& telecommunication Engineering G. H. Raisoni Institute of Engineering and \\ Technology for Women, Nagpur India \\ ${ }^{2}$ Department of Electronics \& telecommunication Engineering G. H. Raisoni Institute of Engineering and \\ Technology for Women, Nagpur India
}

\begin{abstract}
The conventional technique of measuring the quality of water is to gather the samples manually and send it laboratory for analysis, but this technique is time overwhelming and not economical. Since it's not feasible to take the water sample to the laboratory after every hour for measuring it's quality. The water quality measuring system can measure the essential qualities of water in real time. The system consists of multiple sensors to measure the standard of water, microcontroller and GSM to send the information to the watching centre. It's a true time system which is able to endlessly measure the standard of water and can send the measured values to the watching centre when each predefined time. The system relies on microcontroller 8051 and GSM.
\end{abstract}

Keywords: GSM Module, Microcontroller, Multiple sensors, SMS, Water Quality Measuring.

\section{Introduction}

Water quality may be an advanced term to explore. The standard of water depends on such a lot of things. We've used many thought parameters in conjunction with one another to work out the water's quality. These include: $\mathrm{pH}$, turbidity, conductivity, total dissolved solid and temperature. Since the standard technique of water quality measuring isn't economical thus there was a necessity to develop a system which is able to measure the standard of water in real time and also the system must be economical, correct and low price. The water quality measuring system makes use of multiple sensors, information acquisition module and data transmission module. Information acquisition module includes microcontroller 8051. Data transmission module includes GSM module. There are numerous sensors that measures temperature, turbidity, $\mathrm{pH}$, conductivity and total dissolved solid present in the water. This technique conjointly uses ADC. The measured values are then transmitted to the watching centre via GSM; it's conjointly shown on LCD by the microcontroller. The system has the advantage of potency, accuracy and low price.

\subsection{Overall style of the system}

\section{System Hardware Design}

As shown within the diagram the system consists of assorted water quality measuring sensors like $\mathrm{pH}$, turbidity, conductivity and temperature, ADC, microcontroller 8051, GSM module and LCD. The water quality measuring system uses $\mathrm{pH}$, turbidity, conductivity and temperature device to measure the standard of water. This device then measures the corresponding values of the water. Since the outputs of the sensors measured are analog in nature and microcontroller will handle solely digital signals thus there's a necessity of a tool that converts analog signals into digital signals. The system makes use of ADC for this purpose. The outputs of sensors are directly given to ADC, which converts the analog signals into the corresponding digital signals. These digital signals are then given to the microcontroller 8051. System uses GSM module for communication. GSM module makes use of interface of the microcontroller 8051 for communication. Microcontroller sends the measured values to the watching centre by SMS via the GSM module. Since it's a true time system thus microcontroller can send the measured values to the watching centre after the particular time as per the program. With the information to the watching centre the microcontroller conjointly displays the values of the measured quantities on the LCD. It's a true time system thus it doesn't need any man machine interaction for activity the standard of water. 


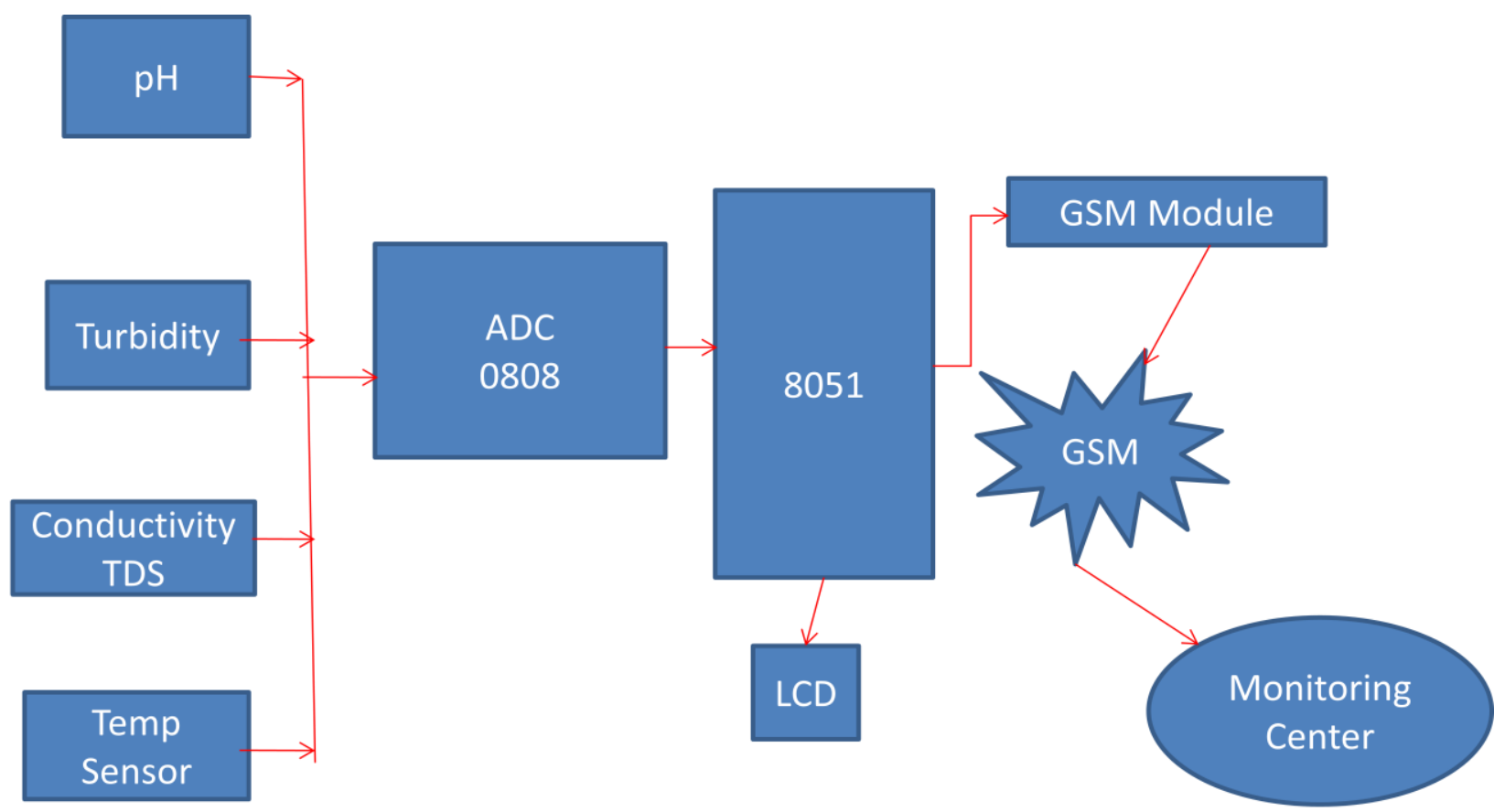

Fig. 1. Block Diagram of the Proposed System

\subsection{Water Quality Detection Sensors}

The system uses sensors to measure 5 qualities of water particularly $\mathrm{pH}$, Turbidity, conductivity, total dissolved solid and temperature.

- $\mathrm{pH}$ may be a measure of the acidity or basicity of associate solution. It's measured by the tactic of electrical potential.

- Turbidity is the measure of water clarity. In alternative words it shows to what extent the water is obvious. These particles decrease the passage of light through the water. Turbidity sensor measures the murkiness by measuring the quantity of light scattered at ninety degree. Turbidity sensor makes use of LDR and LED.

- Conductivity defines the power of the water to conduct electricity. As we all know pure water has poor conductivity thus for water to be pure its ability to conduct current should be poor. Conductivity is measured with the help of two conducting plates.

- Total dissolved solid (TDS) determines the quantity of minerals and salts reside within the water. Total dissolved solid in water will be determined by multiplying the conductivity by a factor and typically this factor is taken as 0.67 .

$$
\text { TDS }=0.67 \mathrm{X} \text { conductivity }
$$

We will not use separate device for determining total dissolved solid in water, we are going to measure conductivity and multiply it by zero.67. This all are going to be done by programming.

- Temperature has a vital influence on water. The system uses LM35 to measure the temperature of water. LM35 is a high precision temperature device.

\subsection{Microcontroller 8051}

Microcontroller has all the features that are found in microprocessor. Microcontrollers are dedicated devices present within an application. The 8051 was introduced by Intel Corporation at the end of 1970s. It is the first microcontroller of MCS-51 family.

Microcontroller has following features:

- 128 bytes of RAM.

- 128 user defined flags.

- 8 bit data bus, 16 bit address bus.

- 3 internal and two external interrupts.

- $4 \mathrm{~K}$ program memory. 
- 16-bit program counter and data pointer.

- 32 general purposes register each of 8 bits.

- Serial communication.

- Two 16 bit inbuilt timers/counters.

- 4 register banks.

\section{Data Transmission Module}

GSM stands for Global System for Mobile Communications. It's used as associate data transmission module. We are going to use GSM SIM 300 Module for the projected system and its figure is shown below.

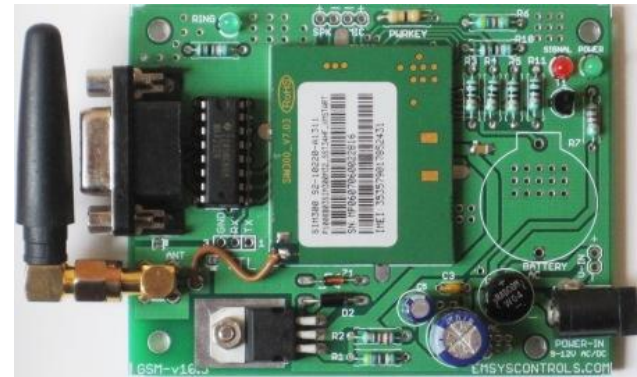

Fig. 2. GSM Sim 300 Module

This module will settle for any GSM network operator SIM card. Advantage of this module is that we are able to use RS232 port to speak. This GSM electronic equipment is extremely versatile plug and play quad band GSM electronic equipment for direct and simple integration to RS232 applications. GSM module uses customary AT commands. A number of the AT commands are given below:-

Table- Some customary AT Commands

\begin{tabular}{|l|l|}
\hline \multicolumn{1}{|c|}{ Command } & \multicolumn{1}{|c|}{ Description } \\
\hline ATA & Answer a call \\
\hline ATD & Dial a number \\
\hline AT+CMGD & Delete Message \\
\hline AT+CSMS & Send short message \\
\hline ATO & $\begin{array}{l}\text { Switch from Command mode } \\
\text { to data mode }\end{array}$ \\
\hline
\end{tabular}

IV. System Software

Microcontroller accepts the values measured by numerous sensors via ADC and send these values to the watching centre by SMS via GSM module. This is all carried out with the help of coding. The code is written in Embedded C and for simulation we tend to use RIDE Software.

\section{Conclusion}

Real time system for water quality measuring based on GSM is associate economical system that uses numerous water detection device and GSM network. The system is incredibly versatile and economical. It's real time system that measures numerous parameters present within the water with the assistance of device and send them to the watching centre mechanically. It doesn't need individuals on duty. Its versatile system as a result of simply by replacement the sensors and by creating some changes within the computer code the system will be created to measure completely different parameters of water. The system is reliable and easy and it will be extended to measure water pollution so on. It's a widespread application. 
6.1 Overall Proposed System

\section{Results}

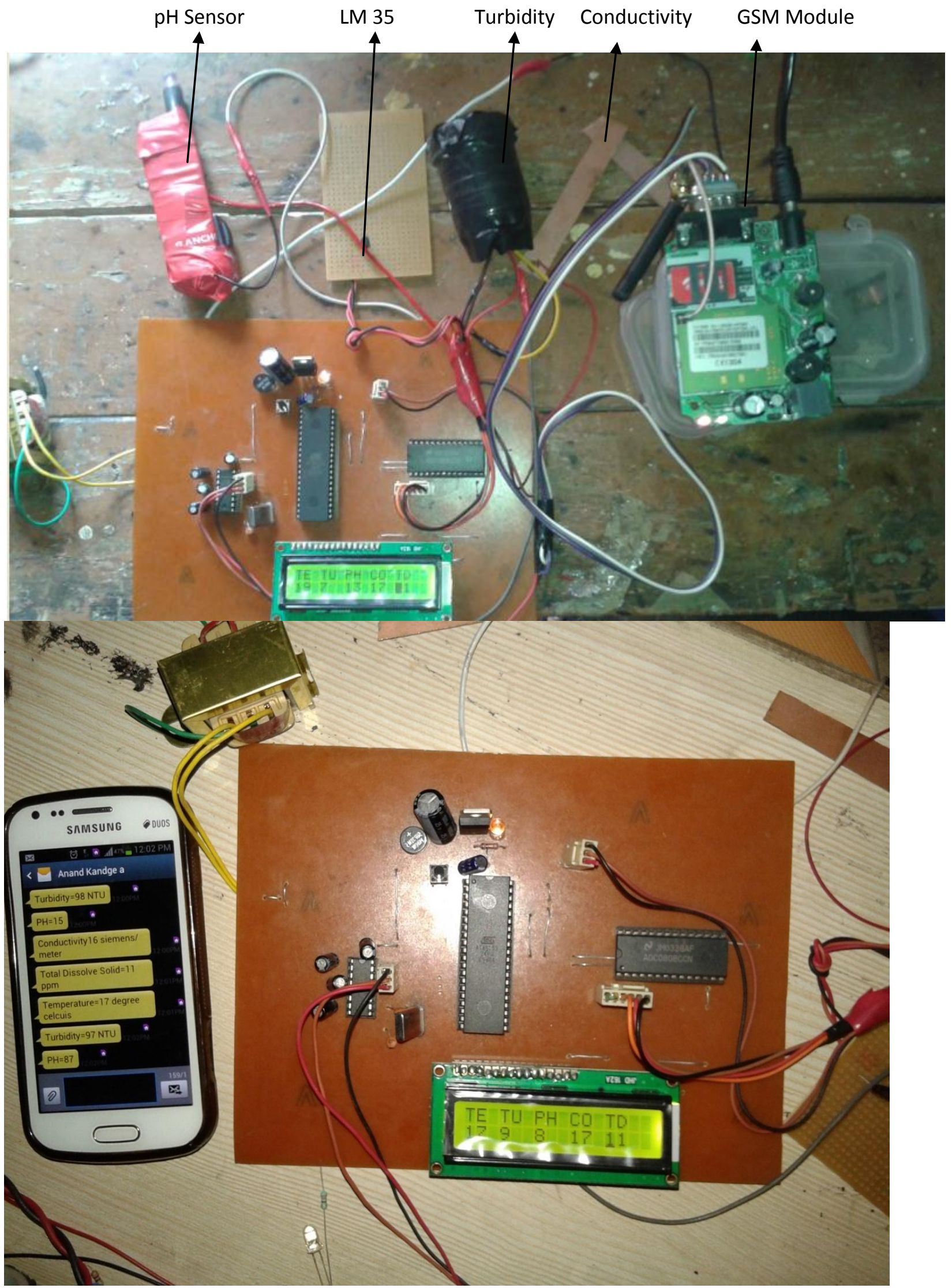


6.2. Measured values on LCD

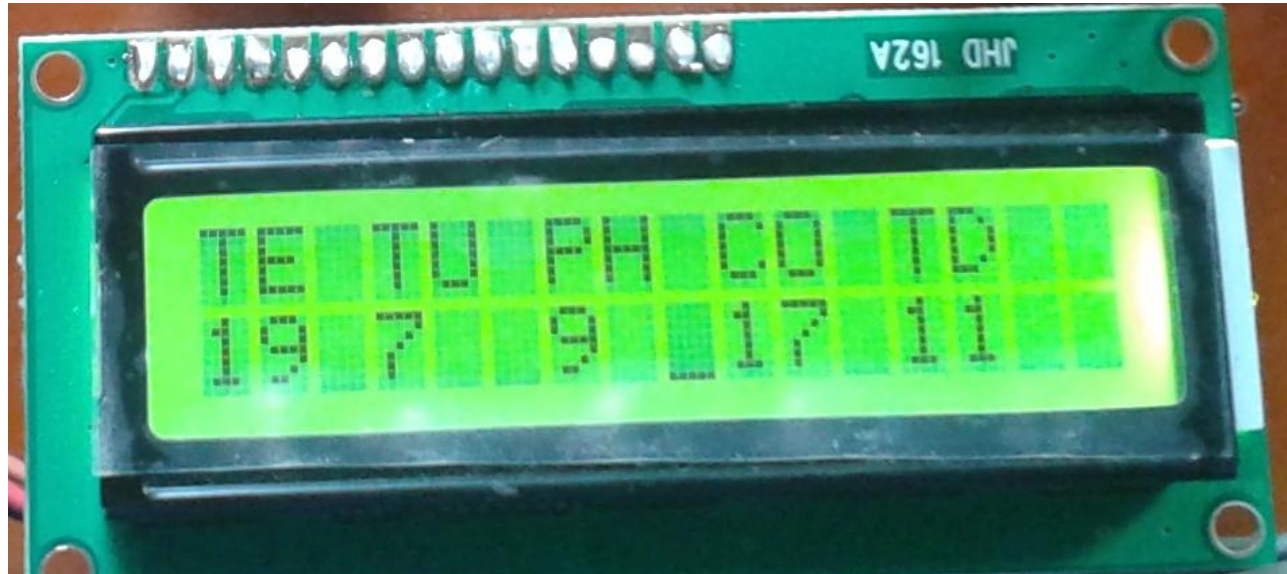

6.3. Measured values on Mobile in form of SMS

\begin{tabular}{|c|c|}
\hline $\begin{array}{l}\text { WATER QUALITY } \\
\text { MEASUREMENT SYSTEM }\end{array}$ & $\begin{array}{l}7 \\
2: 48 \mathrm{PM}\end{array}$ \\
\hline $\begin{array}{l}\text { Temperature }=19 \text { degree } \\
\text { celcuis }\end{array}$ & $\frac{1}{2: 48 P M}$ \\
\hline $\begin{array}{l}\text { Temperature }=18 \text { degree } \\
\text { celcuis }\end{array}$ & $\frac{1}{2: 50 P M}$ \\
\hline Turbidity $=10$ NTU $\int_{2: 50 P M}^{1}$ & \\
\hline$P H=11 \int_{2: 51 P M}^{1}$ & \\
\hline $\begin{array}{l}\text { Conductivity } 17 \text { siemens/ } \\
\text { meter }\end{array}$ & $\begin{array}{l}\mathbf{1} \\
2: 51 P M\end{array}$ \\
\hline Total Dis & \\
\hline
\end{tabular}

\section{References}

[1] Mo Deqing, Zhao Ying, Chen Shangsong, “Automatic Measurement and Reporting System of Water Quality Based on GSM,” 2012 International Conference on Intelligent System Design and Engineering Application.

[2] Dr. Seema Verma, "Wireless Sensor Network application for water quality monitoring in India," 2012 National Conference on Computing and Communication Systems (NCCCS).

[3] Dong He,Li-Xin Zhang," The Water Quality Monitoring System Based on WSN," 1Institute of Mechanical and electronic information, China University of Geosciences (WuHan), WuHan,China, 978-1-4577-1415-3/12/\$26.00 @2012 IEEE

[4] Nazleeni Samiha Haron, Mohd Khuzaimi B Mahamad, Izzatdin Abdul Aziz, Mazlina Mehat," A System Architecture for Water Quality Monitoring System Using Wired Sensors," Computer and Information Science Department, 978-1-4244-2328-6/08/\$25.00 (C) 2008 IEEE

[5] Xiwu He," Design of Automatic Control system for Waterworks based on PLC," 978-1-4577-0536-6/11/\$26.00 @2011 IEEE

[6] Wang Youshun, Lv Yang, "The application of GSM module in smart home system," Yunnan University, 2009, 31: 119-121. (in Chinese)

[7] Wu Xiaoqing, Huhe Muren, "GSM module communication controlled by single-chip," Nei Mongol Science and Technology and Economic,2010, 2:87-88. (in Chinese) 